\title{
LINFOCITOSIS AGUDA INFECCIOSA CON LESIONES DE ERITEMA MULTIFORME
}

\author{
Por el Dr. JORGE E. HOWARD \\ Hospiral Luis Calyo Mackensa. Cátedra de Pediatría dal prof. A. Ariztia.
}

En 1941, Carl Smith describio un cuadro que denominó linfocitosis infecciosa ${ }^{1}$, caracterizado por ser de curso favorable, sin sintomas o signos clínicos especiales $y$ con una leucocitosis con linfocitosis absoluta. Muy a menudo la enfermedad es tan benigna que se presenta en personas en aparente buen estado de salud, siendo el diagnóstico hecho por un hemograma de rutina. En otras oportunidades han sido descritos como síntomas acompaniantes: fiebre, vómitos, irritabilldad, dolores abdominales difusos, diarrea $^{2} \mathrm{y}$ aun a veces síntomas neurológicos, que han hecho al comienzo pensar en la posibilidad de una poliomielitis ${ }^{3}$. En unos pocos casos han sido descritos síntomas cutáneos, representados por un rash morbiliforme, o bien, por lesiones urticariales. Sin embargo, la mayoría de los casos se presentan sin síntomas y es por este motivo que es difícil precisar la frecuencia de este cuadro, aunque al parecer es más frecuente de to que se describe.

No se conoce el agente etiológico y tanto los estudios bacteriológicos, como los de virus no han logrado aislar un agente causal. Se sabe que se trata de una enfermedad infecciosa y contagiosa, ya que varios autores han relatado epidemias en sanatorios o en grupos familiares ${ }^{4}$, pudiendo determinar que el período de incubación es de 12 a 21 días. La enfermedad ataca principalmente a los niños, pero también se han descrito varios casos en jóvenes y aun en adultos

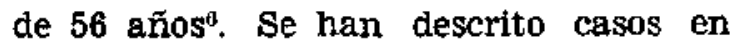
todas las regiones del globo.

El diagnóstico solamente se puede hacer por el estudio del hemograma, que demuestra una hiperleucocitosis, en general sobre 40,000 a 50,000 , debida casi exclusivamente al aumento de los linfocitos, que alcanza porcentajes por encima del $60 \%$. Estos no representan alteraciones en su estructura, son maduros y de variedad pequeña: No existe anormalidad de los elementos rojos ni de las plaquetas. In oportunidades hay un aumento de los eosinófilos, los que se presentan normales, siendo el aumento absoluto más que relativo, ya que el porcentaje en la fórmula persiste igual. El mielograma evidencia una médula normal o hiperplástíca con un aumento del número de linfocitos maduros y normales, alteración que persiste por un tiempo más largo que los cambios encontrados en el hemograma.

La duración de los síntomas clínicos, cuando éstos existen, es de unos pocos días, en tanto que las alteraciones hematológicas duran de una a tres semanas, aunque se han descrito casos que han persistido durante varios meses.

El diagnóstico diferencial debe hacerse con aquellos cuadros que producen una linfocitosis acentuada, a saber: mononucleosis infecciosa, leucemia aguda y coqueluche. Cuando la linfocitosis aguda infecclosa se presenta con sintomatología neurológica o abdominal, podrá pensarse en otros diagnósticos, pero el hemo- 
grama será confirmatorio. En la práctica, los cuadros que pueden prestarse en ocasiones a un diagnóstico diferencial dificil, son la mononucleosis infecciosa $y$ la leucemia aguda. En el primer caso haremos la diferenciación clínica por la adenopatia y esplenomegalia, que duran infecciosa hasta ahora descritas, han si-

nunciada y porque las plaquetas existen en número normal. Además, el mielograma en las leucemias mostrará, fuera de la infiltración de células inmaduras, el hiatus leucémico.

Todos los casos de linfocitosis aguda

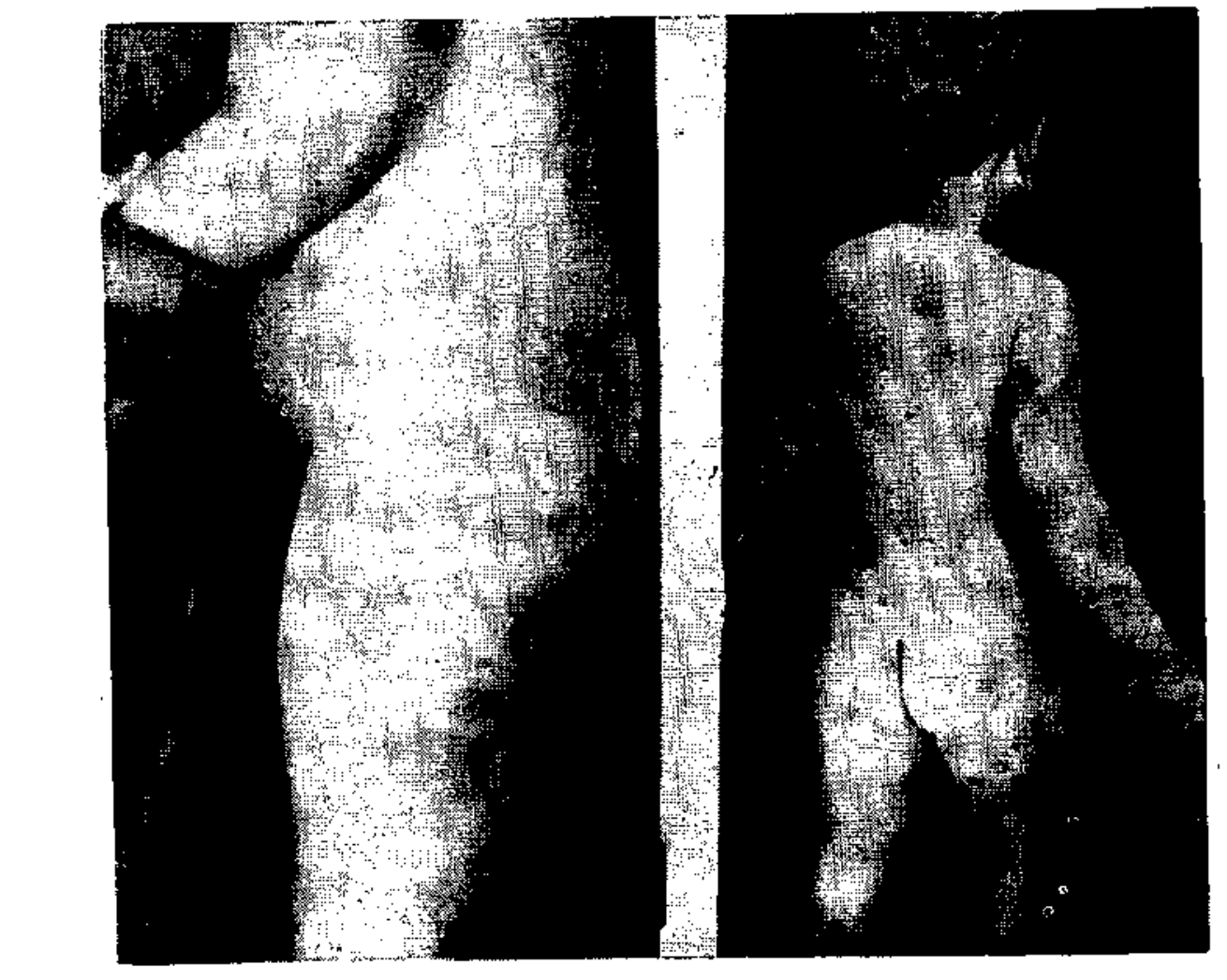

FIG. 1 ,

FIG, 2

varias semanas y que no existen en la linfocitosis aguda infecciosa. También nos podrá ayudar una reacción de Paul Bunnel positiva. El hemograma hará en definitiva el diagnóstico diferencial, ya que en la mononucleosis infecciosa, el número de linfocitosis aumenta discretamente, raramente por encima de 20,000, y los letucocitos característicos son mononucleares grandes, con un núcleo también grande, irregular, con citoplasma vacuolar, que se tiñe intensamente basófilo. Con la leucemia aguda con leucocitosis exagerada, el diagnóstico diferencial se hace por la ausencia de células inmaduras, ya sean linfo o mieloblastos, por la ausencia de anemia pro- do de pronóstico benigno. No se conoce tratamiento efectivo.

Como el caso de linfocitosis aguda infecciosa que tuvimos la oportunidad de estuđiar presenta características especiales, hemos considerado de interés publicarlo.

CASO CLINICO: G. L. O. - Obs. 51/5315.

Concurre por primera vez al Hospital Luis CaIro Mackenna el 23 de octubre de 1951, a la edad de 2 años y 4 meses, con la siguiente anamnesis. Hasta 6 días antes de su ingreso estaba en aparente buen estado de salud, pero ese dia, el 17 de octubre, notan un edema palpebral, corrjuntivas Intensamente congestivas y fiebre alta. Durante 2 días continúa con estos sintomas, decaida $y \sin$ apetito. Al tercer día aparece un rash formado por pequeñas lesiones máculo papala- 
res distrlbuidas en todo el cuerpo, salvo cara y cuero cabelludo, poco numerosas, de color rojo, no pruriginosas. En las días siguientes y hasta su ingreso al hospital, estas lestones fueron aumentando en número y sobre todo en tamaño, por un crecimiento eoncéntrico ¥ a medida que crecían cambiaba el color, de un rojo violeta intenso en la periferia de la lesión, hasta un rosado amarillento en la parte céntrica. Al dia siguiente de aparecer las lesiones cutáneas notan la presencia de exema de los lablos, extremidades y vulva. Como continuara con estas sintomas, la traen al hospital.

Anamnesis familiar: Sin importancia. Una hermana de 4 años actualmente con un com- nia lesiones en la mucosa bucal, aunque la faringe estaiba intensamente congestiva. Los exámenes cardiaco, pulmonar y del abdomen no daban signos dignos de mención. Ias extremidades estaban aumentadas de volumen, con un edema duro, que no dejaba la lmpreslón del dedo al comprimirlo; la niña no movia las piernas voluntariamente y la movilización pasiva era dolorosa, sin que hubiera aumento de volumen de las articulaclones. Existía un marcado edema vulvar y numerosas lesiones cutáneas como las ya descritas en la región perivulvar. Con estos sintomas $y$ con el diagnóstico de exitema multiforme, probable sindrome de stevensJohnson, fué haspitalizada, dejándose con un

\begin{tabular}{|c|c|c|c|c|c|}
\hline \multicolumn{6}{|c|}{ Cuadro I } \\
\hline & $25-x$ & $27-x$ & $2-X I$ & Q-XI & 12-XII \\
\hline Glóbulos rojos & $3: 590,000$ & $3.460,000$ & $2.490,000$ & - & 4.250 .000 \\
\hline Leucocitos & 52,000 & 43,300 & 43,200 & 8,700 & 9,000 \\
\hline Hemoglobina & 10,5 & 10 & 9,4 & - & 1,$1 ; 8$ \\
\hline Basóf Los & 0 & $\mathbf{0}$ & 0 & 1 & 0 \\
\hline Easinófilos & 1 & 1 & 1,5 & 0 & 0 \\
\hline Mielocitos & 0 & 0 & 0 & 0 & 0 \\
\hline Juyeniles & 0 & 0 & 0 & 0 & 0 \\
\hline Baciliformes & 4 & 1 & 1 & 6 & 5 \\
\hline Segmentados & 5 & 7 & 12,5 & 39 & 54 \\
\hline Linfocitos & 88,5 & 89.6 & 82,5 & 49 & 36 \\
\hline Monocitos & 1,5 & 1,5 & $2 ; 5$ & 5 & 5 \\
\hline Plaquetas & normales & normales & normales & - & normales \\
\hline
\end{tabular}

plejo primario tuberculoso en evoluclón; en la casa vivia un enfermo con tuberculosis pulmonar.

Anamnesis personal: sin importancia.

Al examen de ingreso constatamos una niña en buen estado nutritivo, con un peso de $11.500 \mathrm{~kg}$, en posiclón activa. psiquis lúcldo, con temperatura de $37.7^{\circ}$ axtlar. En Ia piel llamaha la atencíón la presencia, de grandes lesiones maculares, de formas redondeadas o en placas, formadas por anillos concéntricos, que cambiaban de color desde un rojo intenso, casl violáceo, a un centro más pálido. Las lesiones tenian contornos solevantados, no eran prurfeinosas ni dolorosas a la presión. Estaban distribuidas en todo el cuerpo, siendo más grandes en las regiones cercanas al codo y a la cadera, más pequeñas en el tórax y plemas. (Ver flguras Nos. 1 y 2).

Tenia una intensa congestión conjuntival bilateral, tanto de la confuntiva palpebral como de la oculat, pero sin secrecion. No te- réglmen blando y $0,025 \mathrm{~g}$ de dimetil-pyriđtlcloro-thenil-etilendiamino (Thenclor) cada 8 horas. En la sala siguló con temperaturas bajas inferiores a $38^{\circ}$ durante los primeros 7 dias. Al comlenzo las lestones cutáneas con las caracteristicas descritas, siguleron aumentando en tamaño y aparecleron unas pocas lesiones nuevas. El crecimiento era concéntrico y a medida que crecian, el centro palídecia, adoptando el aspecto de una equimosis en reabsorción. Poco a poco las lesiones fueron desapareciendo $y$ al cabo de 10 dias sólo quedaba una lígera plgmentación más oscura en el sitio de las lesiones eritematosas. En edema de las extremtdades, igual que la conjuntivitis y el edema vulvar, regresaron en 4 dias.

Al segundo dia de hospitalización un hemograma reveló una leucocitosls de $\mathbf{5 2 , 5 0 0}$ con un $88.5 \%$ de linfocitos maduros normales, pequeños, con una ligera anemia de $3.590,000$. con $10,5 \mathrm{~g}$ de $\mathrm{Hb}$ y con plaquetas normales. Hicimos entonces el diagnóstico 
de Infocitosis aguda infecclosa y suspendimas la medícactón antihistaminica, dándole gluconato de calcio a tomar. En los días siguientes y en correspondencia con la desaparición de las lesiones de eritema exudativo, los hemogramas de control revelaron una dismlnución de la leucocitosis y de la linfocitosis y una acentuactón de su anemla, con plaquetas normales, hasta llegar a cifras normales a las 17 días de hospitalización. (Ver cuadro $\mathrm{N}^{\mathrm{n}}$ I). Un mlelograma hecho entre el segundo $y$ tercer hemograma reveló una médula hiperplástica con 379,000 elementos por $\mathrm{mm}^{3}$, con aumento de los mlelocitos neutrofilos, promielocitos y linfocitos. Durante el curso de la hospitalización se hi- so de la primera semana de enfermedad. También Yaskis ${ }^{\triangleleft}$ relata el caso de un hombre de 29 años, que 2 semanas antes de hacerse en él el diagnóstico de linfocitosis aguda infecciosa, tuvo un rash que duró 2 días y estaba formado por máculo pápulas, localizadas a la mitad inferior del abdomen, caderas, muslos y piernas, agrupándose, especialmente en las piernas, formando manchas grandes de forma variada.

En niños, Landolt describe 3 casos con lesiones urticariaies transitorias $\mathrm{y}$

\section{Cuadro II}

Tlempo coagulación:

Tiempo sangria:

Protrombina:

Activldad tromboplástica:

Proteinemia:

Sedimentación:

Kahn y Kline:

Takata-Ara, Hanger, Timol:

Orina:

Deposiciones:

Cultivo faringe:

Cuitivo deposiciones:
3 minutos.

$3 \frac{1}{2}$ minutos.

$100 \%$.

$2,5 \mathrm{U}$.

$52,5 \% \%$.

22 minutos en 1 hora.

negativas.

negatives.

nommal.

normal.

estafllococos, Pfeiffer, Piociánleo.

enterococo. cieron varios otros exámenes de Jaboratorio, todos ellos con resultados sensiblemente normales. (Ver cuadro $\mathrm{N}^{*}$ II). $\mathrm{A}$ los 11 días fué dada de alta, síendo el examen físico negat1vo, salvo la zona pigmentada, en correspondencia con sus antiguas lesiones eritematosas. La nina ha sido controlada a intervalos semanales y ha seguldo bien, no ha vuelto a presentar lesiones cutáneas y en un hemograma hecho el 12 de diclembre incluso ha reparado su anemia.,

\section{Discusión.}

Revisando la literatura no nos hemos encontrado con ningún caso de linfocitosis aguda infecciosa con lesiones cutáneas, como la de nuestra enfermita, es decir, con lesiones de eritema multiforme. En adultos, Duncan ${ }^{7}$ ha descrito 1 caso que tuvo un rash morbiliforme, que duró alrededor de 4 días en el cur-
1 con lesiones tan acentuadas que motivaron su ingreso al hospital. Garrahan y Bonduel ${ }^{1 "}$ describen el caso de un niño de 6 años, con linfocitosis aguda infecciosa, que presentó también un rash morbiliforme

En nuestro caso las lesiones son diferentes a las señaladas por los autores nombrados, ya que son típicas de un eritema multiforme, que como sabemos, se clasifica no como un cuadro nosológico, sino, como todos los eritemas, más bien como una reacción cutánea a diversos estímulos internos o externos, dependiendo el tipo de lesión de diversos factores, entre los que se encuentran: la naturaleza del estímulo, el sitio anatómico, el estada circulatorio y una predisposición individual. El eritema multiforme está catalogado como un eritema tóxico, sien- 
do una respuesta cutánea a focos de infección, a medicamentos o trastornos gastro intestinales. La lesión patognomónica, que no siempre está presente, es el iris o lesión en tiro al blanco, consistente en un anillo rojizo dentro de otro anillo. Cuando las lesiones cutáneas son circulares con crecimiento concéntrico y blanqueamiento central, como en nuestro caso, al eritema muitiforme se le llama eritema circinata, cuyas lesiones cutâneas son precedidas o acompañadas en un $50 \%$ de los casos de fiebre, malestar, dolores reumatódeos $\mathrm{y}$ otros sintomas constitucionales. La mucosa de los labios, la conjuntiva y la mucosa vaginal también se comprometen en la mitad de los casos. Cuando la sintomatología de las mucosas se exacerba y hay fiebre alta, compromiso del estado general, estomatitis y sobre todo conjuntivitis purulenta, se habla de sindrome de Stevens-Johnson o eritema multiforme exudativo grave. En los casos corrientes todos estos síntomas duran de una a cuatro semanas y al desaparecer las lesiones cutãneas dejan una hiperpigmentacion in situ.

No podemos, por lo tanto, dudar que nuestra enferma presentaba un eritema multiforme y que los sintomas eran atribuibles a ese cuadro, pero el hemograma y mielograma nos confirman que estábamos en presencia de una linfocitosis aguda infecciosa. Que la linfocitosis fuera secundaria al eritema multiforme es muy improbable, ya que tanto en él como en el Stevens-Johnson, encontramos una neutrofilia11, y es más lógico pensar que se tratara de una linfocitosis aguda infecclosa, que dió lesiones cutáneas y generales de eritema multiforme del tipo eritema circinata, posibilidad hasta ahora no descrita $y$ que debe tenerse en cuenta. El hecho que nuestra enferma haya presentado anemia, aunque no es lo corriente dentro de la sintomatología de la linfocitosis aguda infecciosa, puede ocurrir, como ya lo ha hecho notar Lamy ${ }^{12}$ en uno de los casos por él descritos.

\section{Resumen.}

Se presenta un caso de linfocitosis aguda infecciosa con lesiones de eritema multiforme en una niña de $2 \frac{1}{2}$ años. Se revisa la literatura, no encontrándose un caso semejante.

\section{Summary.}

The author reports a case of Acute infectious Lymphocytosis with clinical manifestations of erythema multiforme, in a $2 \frac{1}{2}$ year old child. No similar case was found in a review of the literature.

\section{Bibliografía.}

1.- SMITH, C. H. - Infectious Lymphocytosis. Am. J. Dis. Child, 62: 231, 1941.

2-PETERMAN, M. G.; KOSTER, J. D.; GECFT, E. A and LAMBERT, G. $2 .-$ An opidemic of Infectious Lymphocytosis with diarrhea. Pediatrics 3: 214, 1949.

3.-BELOFF, J. S. and GANG, K. M. Acute Poliomyelitis and Acute Infectious Lymphocytos!s, apparent simoultaneous accurence in 8 summer Camp. J. of Pediatrics $26: 586,1945$.

4.-FINCCANE, D. L. and PHIIITPS, R, I. Infectious Lymphocitosis. A. J. Dis. Children 68: 301, 1944 .

E. LEMON, B. $K$ and KAMMP, D, H. Infectious Lymphocitosis. $J$. of Pediatries 36: 61, 1950.

6.-BARNES, G.; YANNET, G. and LIEBERMAN, R. - A clinical study of an institutional outbreak of Acute Infectious Lymphocytosis. Am. J. Med. Sc. 218: 646, 1849 .

7.-DUCAN, P. A. - Acute Infectious Iymphocytosis in a young adult. N. Eng. J. Med. 233: 177, 1945.

8.-YASKIS, A. S. - Acute Infectious Lymphocytosis in an axdult. J. A. M. A. 132: 638, 1946.

9.-LANDOLT, R. L. - Akute infectiose Lymphocytosen im Kindesalter. Helv. Pediat. Acta 2: 377, 1947.

10--GARRAHAN, J. P. y BONDUEd, A. A. - Linfocitosis aguda infecciosa. Arch. Arg. de Pediat. 88: 1950.

11.-HOWARD, J. E and PEDVIS, S. - Severe Erythema multiforme. (stevens Johnson Syndrome) in Childhood. A. Jour. Dis. Child, 75: 695, 1948.

12.-LAMY. M. - Six observations de Lymphocytose Infertlous Aigue. Areh. Franc. de Pediat. 212: 1848. 